\title{
A Bacteriological Study of Neonatal Septicaemia
}

\author{
Pradnya Naik ${ }^{1 *}$ and Vishwanath Sannayya ${ }^{2}$ \\ ${ }^{1}$ Department of Microbiology, Goa Medical College, Bambolim, Goa 403202, India \\ ${ }^{2}$ Health Quest Diagnostics, Panjim, Goa-403001, India \\ *Corresponding author
}

\section{Keywords}

neonatal infection, septicaemia, blood culture, konkan, BACTEC, VITEC, antibiotic resistance

\section{Article Info}

Accepted: 05 February 2020 Available Online: 10 March 2020

\section{A B S T R A C T}

Neonatal sepsis is defined as a bacterial infection of the blood in an infant younger than 4 weeks of age. Blood cultures remain the mainstay of laboratory diagnosis of bloodstream infections (BSIs) in infants. The knowledge of bacteriological profile and its antibiotic sensitivity patterns is of immense help in saving lives of neonates with septicaemia. The study was conducted on neonatal blood samples to identify the common pathogens as well as rare and newer pathogenic species causing neonatal septicaemia along with their antibiotic sensitivity to help formulate guidelines for empiric antibiotic therapy in a developing country. A retrospective study was carried out on neonatal septicaemia for a period of two years from 2018 to 2019 on total 746 blood samples of neonates from konkan region at a private Microbiology lab in North Goa. Blood samples were processed for identification of pathogens along with antibiotic sensitivity by BACTEC and VITEK automated machines. Out of the 746 blood samples received $77(10.3 \%)$ samples showed growth of pathogenic organisms. 65 isolates were gram negative and 12 were gram positive. Amongstgram negative organisms Klebsiellapneumonia (28.6\%) and Pseudomonas species $(24.7 \%)$ were most commonly isolated and amongst the gram positive were CONS (5.2\%) and MRSA (3.9\%).Pandorea species and Ralstoniapickettii were the newer pathogens isolated. Gram negative organisms showed highest resistance to Beta lactamase inhibitors (86.7\%), Cephalosporins (75.6\%)and Gentamicin (75.4\%)and sensitivity to Carbapenemes and Colistin whereas gram positive organisms showed overall resistance to Beta lactam inhibitor Benzyl Penicillin (83.3\%) and to Ciprofloxacin (66.7\%) and sensitivity to Glycopeptides like Teicoplanin and Vancomycin. Resistance of common pathogens to multiple antimicrobial agents along with emergence of newer pathogens is a great challenge to the effective management of neonatal septicaemia, hence formulation of rational antibiotic policy is important to guide the clinicians regarding both the empirical and definitive treatment.

\section{Introduction}

Neonates are particularly vulnerable to infections because of weak immune barrier. Moreover several risk factors have been identified in the neonates and mothers which make them susceptible to infections. Neonatal septicaemia is responsible for approximately $25 \%$ of the neonatal deaths in the world ${ }^{1}$ and mostly in developing countries. ${ }^{2}$ Neonatal 
sepsis is defined as a bacterial infection of the blood in an infant younger than 4 weeks of age. Blood cultures remain the mainstay of laboratory diagnosis of bloodstream infections (BSIs) in infants.

The pattern of organisms causing infections changes geographically as well as in the same place over a period of time. In addition, the emergence of resistant organisms to antimicrobial agents has become a major threat. For the success of early empiric treatment, periodic evaluation of cases to assess any changing trends in the infecting organisms and their antimicrobial susceptibility is important. Recovery of a pathogen is advantageous, as it confirms the diagnosis of bacteraemia and allows for identification and susceptibility testing on the organism to optimize antimicrobial therapy and duration. Similarly, a negative blood culture is important, as it rules out cases of bacteraemia and prompts continued investigation of other infectious or noninfectious aetiologies or cessation of unnecessary empirical antimicrobial therapy.

The knowledge of bacteriological profile and its antibiotic sensitivity patterns is of immense help in saving lives of neonates with septicaemia. ${ }^{3}$ This study was conducted on neonatal blood samples to identify the common pathogens and some rare and newer pathogenic species causing neonatal sepsis along with their antibiotic sensitivity to help formulate guidelines for empiric antibiotic therapy for neonatal sepsis in a developing country.

\section{Materials and Methods}

A retrospective study on neonatal septicaemia was carried out at a private Microbiology lab in north Goa over a period of two years 2018 to 2019 . We received 746 total samples during this period; out of which
77 samples showed growth of pathogens. Samples received were from konkan areas ie. North Goa district of Goa and Sawantwadi district of Maharashtra. Patients admitted in NICU with clinical signs and symptoms of infections like poor feeding, lethargy, hypothermia or fever, jaundice, bradycardia or tachycardia, respiratory distress, abdominal distension, vomiting, convulsions, oliguria were included. The predominant risk factors were low birth weight and prematurity. Birth asphyxia, premature rupture of membranes (PROM) and Pregnancy induced hypertension were also significant. Blood samples of these neonates were sent to our lab for further processing by BACTEC and VITEK automated machines.

Blood samples with clinical symptoms and signs of septicaemia were collected with aseptic precautions. $5 \mathrm{ml}$ blood was collected into the BD BACTEC TM PedsPlus TM/ F culture bottles which were loaded in BACT/ALERT 3D machine of BIOMERIEUX company as per manufacturer's instructions. Samples positive on BACTEC were inoculated on blood and Mackonkey media. Further Identification of growth from the above media as well as antibiotic sensitivity was done by VITEK 2COMPACT OF BIOMRIEUX company as per manufacturer's instructions.

\section{Results and Discussion}

Out of the 746 samples received, growth of pathogenic organisms was seen in 77 (10.3 $\%)$ samples. 65 isolates were gram negative and 12 isolates were gram positive as shown in table no. 1. Amongst gram negative organisms Klebsiella pneumoniae (28.6\%) and Pseudomonas species $(24.7 \%)$ were most commonly isolated pathogens followed by Escherichia coli (7.8\%), Acinetobacter baumanii, Elizabeth Kingiameningo septica, Burkholderia cepacia, Enterobacter cloacae 
and Serratia marcescens. Pseudomonas putida, Burkholderia gladioli, Pandorea species and Ralstonia pickettii were other rare organisms isolated. Amongst the gram positive organisms MRSA, CONS, Staphylococcus haemolyticus, Enterococcus faecalis and Streptococcus sanguinis were the pathogens isolated.

Tables 2,3,4 and 6 show antibiotic sensitivity pattern of gram negative organisms to various group of drugs tested. Amongst the Klebsiella pneumoniae most of the isolates were resistant to Beta lactams (81.8\%), Cephalosporins $\quad(72.7 \%$ resistant to Cefuroxime) and sensitive to Carbapenes. Most of the Pseudomonas isolates were resistant to Aminoglycosides like Amikacin $(80 \%)$ and Gentamicin (85\%) and responding better with high end drugs like Colistin. Escherichia coli were sensitive to most of the antibiotics except Amoxicillin-Clavulanic acid (100\%). So Klebsiella pneumonia and Escherichia coli respond well to Carbapenem antibiotics. Elizabeth Kingiameningo septica, Serratia marsescens and Pandoraea species were resistant to most drugs except Colistin. Burkholderia gladioli were found to be sensitive to most of the drugs. However, Burkholderia cepacia and Enterobacter cloacae showed resistance to Beta lactam inhibitors, Cephalosporins and Carbapenes and sensitivity to Colistin only. However Ralstonia pickettii showed sensitivity to most of the antibiotics. Overall Gram negative organisms showed highest resistance toBeta lactamase inhibitors like AmoxicillinClavulanic acid (86.7 \%), Cephalosporins $(75.6 \%)$ and Gentamicin $(75.4 \%)$ and sensitivity to Carbapenemes and Colistin.

Table.5 and 7 shows antibiotic sensitivity pattern of gram positive organisms. Overall resistance of Gram positive organisms to Beta lactam inhibitor Benzyl Penicillin was $83.3 \%$ and to ciprofloxacin was $66.7 \%$.Most of the isolates showed sensitivity to the commonly tested drugs especially Glycopeptides like Teicoplanin and Vancomycinas well as Oxazolidinone like Linezolid.

In our study over a period of 2 years incidence of neonatal septicaemia confirmed by culture was $10.3 \%$. Some reports from home and abroad show the incidence of neonatal septicaemia to vary between $36 \%$ to 55\%. However, Movahedian AH et al., reported the prevalence of neonatal septicaemia as $6.6 \%$ and $4.4 \% .^{5}$ Also our study findings show, neonatal septicaemia by gram negative organisms $(84 \%)$ more predominant than gram positive organisms(16\%). In developing countries, gram-negative organisms may be far more prevalent as neonatal pathogens, with a higher incidence of antimicrobial resistance as reported by Desai et al., and couto et al., ${ }^{6 \& 7}$

Septicaemia has been classified as early onset septicaemia (EOS) and late-onset septicaemia (LOS). ${ }^{8}$ The microorganisms most commonly associated with EOS include Group B Streptococcus (GBS), Escherichia coli, Coagulase negative Staphylococcus species (CONS), Haemophilus influenza and Listeria monocytogenes and LOS caused by CONS, S. aureus, E. coli, Klebsiella species, Pseudomonas species, Enterobacter species, Candida species , Serratia species, Acinetobacter species and anaerobes. ${ }^{9}$

Findings of our study show Klebsiella pneumoniae $(28.6 \%)$ as the most frequent isolate and this is in accordance with other Indian studies; ${ }^{10}$ followed by Pseudomonas species and Escherichia coli. With the introduction of antimicrobial agents, Gram negative bacteria like E. coli, Pseudomonas and Klebsiella have become the major threat to the ill, fragile and debilitated newborns in the NICU. ${ }^{11}$ Amongst gram positive 
organisms CONS, MRSA and Staphylococcus haemolyticus were predominant organisms; some studies have shown predominance of infection by CONS. ${ }^{12}$ This bacterium is often regarded as a contaminant, possibly from the skin, however Leon et al., opined that the presence of this bacterium in the blood can no longer be taken as contamination especially in patients admitted in critical care units. ${ }^{13}$ The colonisation of the skin and nasopharynx by CONS and S. aureusin health care workers, overcrowding in nurseries and NICU, and improper hand washing techniques may lead to transmission of Gram-positive organisms in neonates horizontally. The spectrum of bacteria causing neonatal septicaemia in our hospital is comparable to that of National Neonatal Perinatal Network Database report. $^{14}$

The major gram positive isolates viz. $S$. aureus and CONS showed high resistance to beta lactam inhibitors and Ciprofloxacin. High frequency of resistance against the beta lactam and non-beta lactam antibiotics have been seen in MRSA and CONS. ${ }^{15}$ our strains showed sensitivity against Vancomycin or Teicoplanin these drugs therefore can be effectively used if Methicillin resistance is suspected during treatment. All the Grampositive isolates were sensitive to Vancomycin similar to a study by Hoogen $e t$ al., 16

The high frequency of resistance to Beta lactam antibiotics by gram negative organisms can well be due to their indiscriminate use as first line drugs. Amongst the Klebsiella pneumoniae most of the isolates were resistant to Cephalosporins and sensitive to Carbapenes.

Table.1

\begin{tabular}{|l|l|}
\hline Gram Positive Organism & No. $=\mathbf{6 5}(\mathbf{8 4 . 4 \% )}$ \\
\hline Klebsiella pneumoniae & $22(28.6 \%)$ \\
\hline Pseudomonas aeruginosa & $19(24.7 \%)$ \\
\hline Pseudomonas putida & $01(1.3 \%)$ \\
\hline Escherichia coli & $06(7.8 \%)$ \\
\hline ElizabethKingiameningo septica & $03(3.9 \%)$ \\
\hline Burkholderia cepacia & $03(3.9 \%)$ \\
\hline Enterobacter cloacae & $03(3.9 \%)$ \\
\hline Acinetobacterbaumanii & $03(3.9 \%)$ \\
\hline Serratia marcescens & $02(2.6 \%)$ \\
\hline Burkholderia gladioli & $02(2.6 \%)$ \\
\hline Pandoraea species & $01(1.3 \%)$ \\
\hline Ralstonia pickettii & $01(1.3 \%)$ \\
\hline Gram positive organism & No.=12(15.6\%) \\
\hline CONS & $04(5.2 \%)$ \\
\hline MRSA & $03(3.9 \%)$ \\
\hline Staphylococcus haemolyticus & $03(3.9 \%)$ \\
\hline Streptococcus sanguinis & $01(1.3 \%)$ \\
\hline Enterococcus faecalis & $01(1.3 \%)$ \\
\hline
\end{tabular}


Table. 2 antibiotic sensitivity pattern of gram negative organisms

\begin{tabular}{|c|c|c|c|c|c|c|c|c|c|c|c|c|}
\hline \multirow[t]{2}{*}{ Antibiotic } & \multicolumn{3}{|c|}{$\begin{array}{c}\text { Klebsiella } \text { species } \\
\mathbf{n}=22\end{array}$} & \multicolumn{3}{|c|}{$\begin{array}{c}\text { Pseudomonas species } \\
\mathrm{n}=20\end{array}$} & \multicolumn{3}{|c|}{$\underset{n=6}{\text { Escherichia }}$ coli } & \multicolumn{3}{|c|}{$\begin{array}{l}\text { Acinetobacter species } \\
\qquad \mathrm{N}=3\end{array}$} \\
\hline & $\mathrm{R}$ & S & I & $\mathrm{R}$ & $\mathrm{S}$ & I & $\mathrm{R}$ & $\mathrm{S}$ & I & $\mathrm{R}$ & $\mathrm{S}$ & I \\
\hline $\begin{array}{l}\text { Amoxycillin - } \\
\text { clavulanic acid }\end{array}$ & $18(81.8 \%)$ & 2 & 2 & - & - & - & $6(100 \%)$ & 0 & 0 & $2(66.6 \%)$ & 1 & 0 \\
\hline $\begin{array}{l}\text { Piperacillin- } \\
\text { tazobactam }\end{array}$ & $10(45.5 \%)$ & 9 & 3 & $16(80 \%)$ & 3 & 1 & $1(16.7 \%)$ & 5 & 0 & $2(66.6 \%)$ & 1 & 0 \\
\hline $\begin{array}{l}\text { Cefoperazon- } \\
\text { salbactam }\end{array}$ & $10(45.5 \%)$ & 7 & 5 & $8(40 \%)$ & 2 & 10 & $2(33.3 \%)$ & 4 & 0 & 0 & 3 & 0 \\
\hline Cefuroxime & $16(72.7 \%)$ & 6 & 0 & - & - & - & $2(33.3 \%)$ & 4 & 0 & $3(100 \%)$ & 0 & 0 \\
\hline Cefepime & $12(54.5 \%)$ & 10 & 0 & $8(40 \%)$ & 11 & 1 & $1(16.7 \%)$ & 4 & 1 & $1(33.3 \%)$ & 2 & 0 \\
\hline Meropenem & $8 \quad(36.4 \%)$ & 14 & 0 & $6(30 \%)$ & 6 & 8 & $1(16.7 \%)$ & 5 & 0 & $2(66.6 \%)$ & 1 & 0 \\
\hline Imipenem & $8(36.4 \%)$ & 14 & 0 & $12(60 \%)$ & 5 & 3 & $1(16.7 \%)$ & 5 & 0 & 0 & 2 & 1 \\
\hline Ertapenem & $8(36.4 \%)$ & 14 & 0 & - & - & - & $1(16.7 \%)$ & 5 & 0 & $3(100 \%)$ & 0 & 0 \\
\hline Ciprofloxacin & $9 \quad(40.9 \%)$ & 4 & 9 & $5(25 \%)$ & 6 & 9 & $2(33.3 \%)$ & 4 & 0 & 0 & 3 & 0 \\
\hline Amikacin & $2(9.1 \%)$ & 20 & 0 & $16(80 \%)$ & 3 & 1 & $2(33.3 \%)$ & 4 & 0 & $1(33.3 \%)$ & 2 & 0 \\
\hline Gentamicin & $12(54.5 \%)$ & 10 & 0 & $17(85 \%)$ & 2 & 1 & $6(100 \%)$ & 0 & 0 & $2(66.6 \%)$ & 1 & 0 \\
\hline Cotrimazole & $13(59.1 \%)$ & 9 & 0 & $6(30 \%)$ & 14 & 0 & $1(16.7 \%)$ & 5 & 0 & $1(33.3 \%)$ & 2 & 0 \\
\hline Colistin & 0 & 22 & 0 & 0 & 20 & 0 & 0 & 6 & 0 & 0 & 3 & 0 \\
\hline
\end{tabular}

$\mathrm{R}=$ resistant $\mathrm{S}=$ sensitive $\mathrm{I}=$ intermediate 
Table.3

\begin{tabular}{|c|c|c|c|c|c|c|c|c|c|c|c|c|}
\hline \multirow[t]{2}{*}{ ANTIBIOTIC } & \multicolumn{3}{|c|}{$\begin{array}{c}\text { Elizabeth } \\
\text { Kingiameningo septica } \\
\mathrm{N}=\mathbf{3}\end{array}$} & \multicolumn{3}{|c|}{$\begin{array}{l}\text { Serratia marcescens } \\
\qquad \mathrm{N}=2\end{array}$} & \multicolumn{3}{|c|}{$\begin{array}{l}\text { Burkholderia cepacia } \\
\qquad \mathrm{N}=3\end{array}$} & \multicolumn{3}{|c|}{$\begin{array}{l}\text { Burkholderia gladioli } \\
\qquad \mathrm{N}=2\end{array}$} \\
\hline & $\mathrm{R}$ & $\mathrm{S}$ & I & $\mathrm{R}$ & $\mathrm{S}$ & I & $\mathrm{R}$ & $\mathrm{S}$ & I & $\mathrm{R}$ & $\mathrm{S}$ & I \\
\hline $\begin{array}{l}\text { Amoxycillin - } \\
\text { clavulanic acid }\end{array}$ & $3(100 \%)$ & 0 & 0 & $2(100 \%)$ & 0 & 0 & $3(100 \%)$ & 0 & 0 & 0 & 2 & 0 \\
\hline $\begin{array}{l}\text { Piperacillin- } \\
\text { tazobactam }\end{array}$ & $3(100 \%)$ & 0 & 0 & $2(100 \%)$ & 0 & 0 & $3(100 \%)$ & 0 & 0 & 0 & 2 & 0 \\
\hline $\begin{array}{l}\text { Cefoperazon- } \\
\text { salbactam }\end{array}$ & $3(100 \%)$ & 0 & 0 & $2(100 \%)$ & 0 & 0 & $2(66.6 \%)$ & 0 & 1 & 0 & 2 & 0 \\
\hline Cefuroxime & $3(100 \%)$ & 0 & 0 & $2(100 \%)$ & 0 & 0 & $1(33.3 \%)$ & 2 & 0 & $2(100 \%)$ & 0 & 0 \\
\hline Cefepime & $3(100 \%)$ & 0 & 0 & $1(50 \%)$ & 0 & 1 & $1(33.3 \%)$ & 1 & 1 & 0 & 0 & 2 \\
\hline Meropenem & $3(100 \%)$ & 0 & 0 & $2(100 \%)$ & 0 & 0 & 0 & 3 & 0 & 0 & 2 & 0 \\
\hline Imipenem & $3(100 \%)$ & 0 & 0 & $2(100 \%)$ & 0 & 0 & $2(66.6 \%)$ & 1 & 0 & 0 & 2 & 0 \\
\hline Ertapenem & $3(100 \%)$ & 0 & 0 & $2(100 \%)$ & 0 & 0 & $2(66.6 \%)$ & 1 & 0 & $1(50 \%)$ & 1 & 0 \\
\hline Ciprofloxacin & $3(100 \%)$ & 0 & 0 & 0 & 0 & 2 & $1(33.3 \%)$ & 1 & 1 & 0 & 2 & 0 \\
\hline Amikacin & $3(100 \%)$ & 0 & 0 & $2(100 \%)$ & 0 & 0 & $3(100 \%)$ & 0 & 0 & 0 & 2 & 0 \\
\hline Gentamicin & $3(100 \%)$ & 0 & 0 & $2(100 \%)$ & 0 & 0 & $3(100 \%)$ & 0 & 0 & 0 & 2 & 0 \\
\hline Cotrimazole & $1(33.3 \%)$ & 2 & 0 & $2(100 \%)$ & 0 & 0 & $1(33.3 \%)$ & 2 & 0 & 0 & 2 & 0 \\
\hline Colistin & $1(33.3 \%)$ & 2 & 0 & 0 & 2 & 0 & $1(33.3 \%)$ & 2 & 0 & 0 & 2 & 0 \\
\hline
\end{tabular}

$\mathrm{R}=$ resistant $\mathrm{S}=$ sensitive $\mathrm{I}=$ intermediate 
Table.4

\begin{tabular}{|c|c|c|c|c|c|c|c|c|c|}
\hline \multirow[t]{2}{*}{ Antibiotic } & \multicolumn{3}{|c|}{$\begin{array}{c}\text { Enterobacter cloacae } \\
\qquad \mathrm{N}=3\end{array}$} & \multicolumn{3}{|c|}{$\begin{array}{c}\text { Pandoraea species } \\
\text { N=1 }\end{array}$} & \multicolumn{3}{|c|}{$\begin{array}{l}\text { Ralstonia pickettii } \\
\qquad \mathrm{N}=1\end{array}$} \\
\hline & $\mathrm{R}$ & $\mathrm{S}$ & I & $\mathrm{R}$ & $\mathrm{S}$ & I & $\mathrm{R}$ & S & I \\
\hline $\begin{array}{l}\text { Amoxycillin - } \\
\text { clavulanic acid }\end{array}$ & $3(100 \%)$ & 0 & 0 & $1(100 \%)$ & 0 & 0 & $1(100 \%)$ & 0 & 0 \\
\hline $\begin{array}{l}\text { Piperacillin- } \\
\text { tazobactam }\end{array}$ & 0 & 1 & 2 & $1(100 \%)$ & 0 & 0 & 0 & 1 & 0 \\
\hline $\begin{array}{l}\text { Cefoperazon- } \\
\text { salbactam }\end{array}$ & 0 & 1 & 2 & $1(100 \%)$ & 0 & 0 & 0 & 1 & 0 \\
\hline Cefuroxime & $3(100 \%)$ & 0 & 0 & $1(100 \%)$ & 0 & 0 & $1(100 \%)$ & 0 & 0 \\
\hline Cefepime & $3(100 \%)$ & 0 & 0 & $1(100 \%)$ & 0 & 0 & 0 & 0 & 1 \\
\hline Meropenem & $3(100 \%)$ & 0 & 0 & $1(100 \%)$ & 0 & 0 & 0 & 1 & 0 \\
\hline Imipenem & $3(100 \%)$ & 0 & 0 & $1(100 \%)$ & 0 & 0 & 0 & 1 & 0 \\
\hline Ertapenem & $3(100 \%)$ & 0 & 0 & $1(100 \%)$ & 0 & 0 & 0 & 1 & 0 \\
\hline Ciprofloxacin & 0 & 1 & 2 & $1(100 \%)$ & 0 & 0 & 0 & 1 & 0 \\
\hline Amikacin & 0 & 3 & 0 & $1(100 \%)$ & 0 & 0 & 0 & 0 & 1 \\
\hline Gentamicin & $3(100 \%)$ & 0 & 0 & $1(100 \%)$ & 0 & 0 & 0 & 1 & 0 \\
\hline Cotrimazole & $3(100 \%)$ & 0 & 0 & 0 & 1 & 0 & 0 & 1 & 0 \\
\hline Colistin & 0 & 3 & 0 & 0 & 1 & 0 & 0 & 1 & 0 \\
\hline
\end{tabular}


Table.5 Antibiotic sensitivity pattern of gram positive organisms

\begin{tabular}{|c|c|c|c|c|c|c|c|c|c|c|c|c|}
\hline \multirow[t]{2}{*}{ Antibiotic } & \multicolumn{3}{|c|}{$\begin{array}{c}\text { Staphylococcus } \\
\text { haemolyticus } \\
\mathrm{N}=3\end{array}$} & \multicolumn{3}{|c|}{$\begin{array}{l}\text { Enterococcus faecalis } \\
\qquad \mathrm{N}=1\end{array}$} & \multicolumn{3}{|c|}{$\begin{array}{c}\text { MRSA } \\
\mathbf{N}=\mathbf{3}\end{array}$} & \multicolumn{3}{|c|}{$\begin{array}{c}\text { CONS } \\
\mathrm{N}=4\end{array}$} \\
\hline & $\mathrm{R}$ & $\mathrm{S}$ & I & $\mathrm{R}$ & $\mathrm{S}$ & I & $\mathrm{R}$ & $\mathrm{S}$ & I & $\mathrm{R}$ & $\mathrm{S}$ & I \\
\hline Benzyl Penicillin & $3(100 \%)$ & 0 & 0 & 0 & 1 & 0 & $3(100 \%)$ & 0 & 0 & $4(100 \%)$ & 0 & 0 \\
\hline Gentamicin & $2(66.6 \%)$ & 1 & 0 & 0 & 1 & 0 & $1(33.3 \%)$ & 2 & 0 & $2(50 \%)$ & 1 & 1 \\
\hline Tetracycline & 0 & 3 & 0 & $1(100 \%)$ & 0 & 0 & $1(33.3 \%)$ & 2 & 0 & $1(25 \%)$ & 3 & 0 \\
\hline Teicoplanin & 0 & 3 & 0 & 0 & 1 & 0 & 0 & 3 & 0 & $1(25 \%)$ & 3 & 0 \\
\hline Linezolid & 0 & 3 & 0 & 0 & 1 & 0 & 0 & 3 & 0 & $2(50 \%)$ & 2 & 0 \\
\hline Cotromazole & $2(66.6 \%)$ & 1 & 0 & $1(100 \%)$ & 0 & 0 & $1(33.3 \%)$ & 2 & 0 & 0 & 4 & 0 \\
\hline Clindamycin & $2(66.6 \%)$ & 1 & 0 & $1(100 \%)$ & 0 & 0 & 0 & 3 & 0 & $2(50 \%)$ & 2 & 0 \\
\hline
\end{tabular}


Table.6 Total antibiotic resistance for gram negative organisms

\begin{tabular}{|l|c|c|}
\hline \multicolumn{1}{|c|}{ Antibiotic } & $\begin{array}{c}\text { Number of resistant isolates out } \\
\text { of 65 gram negative organisms } \\
\text { isolated * }\end{array}$ & \% of resistant isolates \\
\hline Amoxycillin - clavulanic acid & 39 & 86.7 \\
\hline Piperacillin-tazobactam & 38 & 58.5 \\
\hline Cefoperazon-salbactam & 28 & 43.1 \\
\hline Cefuroxime & 34 & 75.6 \\
\hline Cefepime & 31 & 47.7 \\
\hline Meropenem & 26 & 40 \\
\hline Imipenem & 32 & 49.2 \\
\hline Ertapenem & 24 & 53.3 \\
\hline Ciprofloxacin & 21 & 32.3 \\
\hline Amikacin & 28 & 43.1 \\
\hline Gentamicin & 49 & 75.4 \\
\hline Cotrimazole & 28 & 43.1 \\
\hline Colistin & 2 & 3.1 \\
\hline
\end{tabular}

*isolates of Pseudomonas species were not tested for Amoxyclav,Cefuroxime and Ertapenem

Table.7 Total antibiotic resistance for gram positive organisms

\begin{tabular}{|l|c|c|}
\hline \multicolumn{1}{|c|}{ Antibiotic } & $\begin{array}{c}\text { Number of resistant } \\
\text { isolates out of 12 gram } \\
\text { positive organisms } \\
\text { isolated }\end{array}$ & \% of resistant isolates \\
\hline Benzyl penicillin & 10 & 83.3 \\
\hline Ciprofloxacin & 8 & 66.7 \\
\hline Gentamicin & 5 & 41.7 \\
\hline Tetracycline & 3 & 25 \\
\hline Teicoplanin & 1 & 8.3 \\
\hline Vancomycin & 0 & 0 \\
\hline Linezolid & 2 & 16.7 \\
\hline Cotromazole & 4 & 33.3 \\
\hline Clindamycin & 5 & 41.7 \\
\hline
\end{tabular}


Most of the Pseudomonas isolates were resistant to Aminoglycosides like Amikacin and Gentamicin and Carbapenems and responding better with Cotrimazole and with high end drugs like Colistin. Escherichia coli were sensitive to most of the antibiotics except Amoxyclav. Gram-negative isolates especially Klebsiella pneumoniae and Pseudomonas except Escherichia coli showed a high resistance to all Cephalosporins which is similar to the resistance pattern reported by Bhat et al., ${ }^{17}$ Klebsiella and Escherichia coli respond well to Carbapenem antibiotics.

Also there is emergence of some newer pathogens like Pandoraea species and Ralstonia pickettii with Pandoraeaspecies showing resistance to all drugs except Colistin. However, Ralstonia pickettii showed susceptibility to most of the drugs. Elizabeth kingiameningiseptica and Serratia marcescens were resistant to most drugs except Colistin. Burkholderia gladioli was sensitive to most of the drugs but Burkholderia cepacia along with Enterobacter cloacae showed resistance to Cephalosporins and Carbapenes and sensitivity to Colistin indicating the importance of speciation amongst the pathogens.

The empirical combination of Cephalosporins like Ceftazidime and Aminoglycosides like Amikacin can provide cover for the majority of the Enterobacteriaceae and nonfermenters. In critically ill neonates Meropenem plus either Gentamycin or Ciprofloxacin and in multi-drug resistant neonates Colistin can be given. Hence antibiotic stewardship, including appropriate choice and administration of antibiotics and a multidisciplinary team approach to managing neonatal sepsis, is recommended to limit inappropriate antibiotic use and prevent the development of resistance. ${ }^{18}$ Although extensive research on neonatal septicaemia is available worldwide and in India; very few studies have been conducted on konkan areas. Hence our approach towards the retrospective study in this area based on the samples received in our lab. The character of data from single centre also limits the generalizability to other geographical areas or institutions.

Advances in newborn intensive care has allowed the survival of infants but at the same time created risks for hospital acquired infections, which are the major cause of mortality. In addition, the emergence of resistant organisms to antimicrobial agents has become a major threat.

Hence, early treatment and appropriate use of antibiotics would reduce the risk of severe morbidity and mortality due to infections, and also the emergence of multi-drug resistant pathogens.

Neonatal septicaemia by gram negative organisms is more predominant than gram positive organisms. Also there is not much published literature on neonatal septicaemia available for the konkan region for comparison of our study with other authors. Our study shows that there is emergence of some newer pathogens raising a serious concern about health and wellbeing of neonates. Also management of infections by emergence of new and rare pathogens is difficult due to their resistance pattern to majority of drugs.

Hence on-going antibiotic surveillance of such infections is a necessity. As resistance to multiple antimicrobial agents is a great challenge to the effective management of infections, formulation of rational antibiotic policy is important to guide the clinicians regarding both the empirical and definitive treatment. Also certain preventive measures 
like hand hygiene, barrier nursing, fumigation of wards and restricted entries in NICU should be enforced strictly.

\section{References}

1. WHO. Newborns: Reducing Mortality. WHO. Available from: http://www.who.int/mediacentre/factshe ets/fs333/en/. [Last cited on 2013 May 25].

2. WHO | Levels and Trends in Child Mortality. WHO. Available from: http://www.who.int/maternal_child_ado lescent/

documents/levels_trends_child_mortalit y_2012/en/index.html. [Last cited on 2013 May 25].

3. Neonatal Sepsis; 2012 July, 12. Available from:

http://emedicine.medscape.com/article/9 78352-overview. [Last cited on $2013 \mathrm{Jul}$ $16]$.

4. Gaynes RP, Edwards JR, Jarvis WR, Culver DH, Tolson JS, Martona WJ. Nosocomial infections among neonates in high risk nurseries in the United States.National Nosocomial Infections Surveillance Systems.

Paediatrics1996;98:357-361.

5. Movahedian AH, Moniri R, Mosayebi Z. Bacterial culture of neonatal sepsis. Iranian JPubl Health. 2006;35(4):84-9.

6. R. C. Couto, E. A. A. Carvalho, T. M. G. Pedrosa, E. R. Pedroso, M. C. Neto, and F. M. Biscione, "A 10-year prospective surveillance of nosocomial infections in neonatal intensive care units,"American Journal of Infection Control,vol.35,no.3,pp.183-189, 2007.

7. Desai KJ, Malek SS. Neonatal septicaemia. Bacterial isolates and their antibiotic susceptibility pattern. NJIRM. 2010;1(3):12-5

8. Ballot DE, Nana T, Sriruttan C, Cooper
PA. Bacterial bloodstream infections in neonates in a developing country. ISRN Pediatr 2012;2012:508512.

9. Hornik CP, Fort P, Clark RH, Watt K, Benjamin DK Jr, Smith PB, et al.Early and late onset sepsis in very-low-birthweight infants from a large group of neonatal Intensive Care Units. Early Hum Dev 2012;88Suppl 2:S69-74.

10. Das PK, Basu K, Chakraborty P, Bhowmik PK. Clinical and bacteriological profile of neonatal infections in metropolitan city based medical college nursery. J Ind Med Assoc 1999;97:3-5.

11. Vinodkumar CS, Kalappaanavar NK, Patil U, Basavrajappa KG. Change in spectrum of microbial etiology in relation to gestational age and birth weight and emergence of ESBL in tertiary neonatal intensive care units. Int JBiol Med. Res. 2011;2(3):727-34.

12. Agnihotri N, Kaistha N, Gupta V. Antimicrobial susceptibility of isolates from neonatal septicemia. Jpn J Infect Dis 2004;57:273-5.

13. Ponce deLeon S, Wenzel RP. Hospital acquired blood stream infections with Staphylococcusepidermidis: Review of 100 cases. Am J Med1984; 77: 639644.

14. Singh M. Care of the Newborn, $5^{\text {th }}$ Ed. ( Sagar Publications, New Delhi ) 1999;198-223.

15. FluitAdC, Jones ME, Schmitz FJ, Acar J, Gupta R, Verkoef J. Antimicrobial susceptibility and frequency of occurrence of clinical blood isolatesin Europe from the Sentry Antimicrobial Surveillance Programme, 1997 \& 1998. Clin Infect Dis2000; 30: 454-460 .

16. Van den Hoogen A, Gerards LJ, Verboon-Maciolek MA, Fleer A, Krediet TG. Long-term trends in the epidemiology of neonatal sepsis and antibiotic susceptibility of causative 
agents. Neonatology 2010;97:22-8.

17. Bhat Y R, Lewis LE, Ke V. Bacterial isolates of early-on set neonatal sepsis and their antibiotic susceptibility pattern between 1998 and 2004: An audit from a center in India. Ital $\mathbf{J}$ Pediatr 2011;37:32.
18. S. J. Patel and L. Saiman, "Antibiotic resistance in neonatal intensive care unit pathogens: mechanisms, clinical impact, and prevention including antibiotic stewardship,"Clinics in Perinatology, vol. 37, no. 3, pp. 547-563, 2010.

\section{How to cite this article:}

Pradnya Naik and Vishwanath Sannayya. 2020. A Bacteriological Study of Neonatal Septicaemia. Int.J.Curr.Microbiol.App.Sci. 9(03): 1121-1132.

doi: https://doi.org/10.20546/ijcmas.2020.903.131 